\title{
A retrospective evaluation of the efficacy of intravenous bumetanide and comparison of potency with furosemide

\begin{abstract}
*
Background: The potency of intravenous bumetanide to furosemide using a ratio of 1:40 has been suggested; however, there are little data supporting this ratio. Recent drug shortages required the use of bumetanide in a large patient population, enabling further characterization of the efficacy of IV bumetanide.

Objective: The primary objective of this study was to estimate a dose-response effect of IV bumetanide on urine output (UOP) in all patients that received 48 hours of therapy as well as in a subgroup of patients with heart failure (HF). This subgroup was used to compare the potency of bumetanide with furosemide. A secondary safety objective described electrolyte replacement required during therapy.

Methods: This was a single-center retrospective study examining the dose-response effect of IV bumetanide in patients receiving at least 48 hours of intermittent (ilV) or continuous (cIV) dosing, measured by UOP per mg of drug received $(\mathrm{mL} / \mathrm{mg})$. The potency of IV bumetanide was compared with furosemide in a subset of patients with HF using pre-existing data. The safety of IV bumetanide was analyzed by quantifying electrolyte replacement received during the study period.

Results: The primary outcome was higher in the ilV group $(\mathrm{n}=93)$ at $1273 \pm 844 \mathrm{~mL} / \mathrm{mg}$ compared with the cIV group $(n=16)$ at $749 \pm 370 \mathrm{~mL} / \mathrm{mg}$ $(P=0.002)$. Among patients with HF who received furosemide (ilV $n=30$, clV $n=26$ ) or bumetanide (ilV $n=30$, cIV $n=3$ ), a potency ratio of $41: 1$ was found for the ilV group and 34:1 for all patients with HF. There was no significant difference in electrolyte replacement between groups.

Conclusion: A greater response was seen with intermittent bumetanide compared with continuous infusion bumetanide. This study supports the 40:1 dose equivalence ratio (furosemide:bumetanide) in patients with HF receiving at least 48 hours of intravenous intermittent bumetanide.
\end{abstract}

Keywords: Bumetanide; Furosemide; Heart Failure; Treatment Outcome; Therapeutic Equivalency
* Jean M. NAPPI. Pharm.D., FCCP, BCPS. Professor of Clinical Pharmacy and Outcome Sciences. South Carolina College of Pharmacy, Medical University of South Carolina Campus. Charleston, SC (United States).

\author{
EVALUACIÓN RETROSPECTIVA DE LA \\ EFICACIA DE LA BUMETANIDA \\ INTRAVENOSA Y COMPARACIÓN DE LA \\ POTENCIA CON FUROSEMIDA
}

\section{RESUMEN}

Antecedentes: Se ha sugerido que existe un ratio de potencia de la bumetanida con la furosemida de 1:40; sin embargo, hay pocos estudios que soporten este ratio. Recientes desabastecimientos requirieron el uso de bumetanida en una población grande de pacientes, lo que permitió una caracterización extensiva de la eficacia de la bumetanida IV.

Objetivo: El objetivo primario de este estudio fue estimar la respuesta dosis-efecto de la bumetanida IV en la diuresis en todos los pacientes que recibieron 48 horas de tratamiento, así como en el subgrupo de pacientes con fallo cardiaco. Este subgrupo fue utilizado para comparar la potencia de la bumetanida con la furosemida. Un objetivo secundario de seguridad describió el reemplazo de electrolitos necesario durante el tratamiento. Métodos: Este fue un estudio unicéntrico retrospectivo que examinó el la respuesta dosefecto de la bumetanida IV en pacientes que la recibieron al menos 48 horas intermitentemente (iIV) o continua (cIV), medida por la diuresis por $\mathrm{mg}$ de medicamento recibido ( $\mathrm{mL} / \mathrm{mg}$ ). La potencia de la bumetanida IV se comparó en la furosemida en un subgrupo de pacientes con fallo cardiaco utilizando datos pre-existentes. La seguridad de la bumetanida IV se analizó cuantificando el reemplazo electrolítico recibido durante el periodo de estudio.

Resultados: El resultado primario fue mayor en el grupo iIV ( $\mathrm{n}=93$ ) con $1273(\mathrm{SD}=844) \mathrm{mL} / \mathrm{mg}$, que en el grupo cIV $(\mathrm{n}=16)$ con $749(\mathrm{SD}=370) \mathrm{mL} / \mathrm{mg}$ $(\mathrm{p}=0,002)$. Entre los pacientes con fallo cardiaco que recibieron furosemida ( $\mathrm{IIV} n=30$, $\mathrm{cIV} n=26$ ) o bumetanida (iIV $n=30$, cIV $n=3$ ) se encontró un ratio de potencia de 41:1 para el grupo iIV y de 34:1 para todos los pacientes con fallo cardiaco. No hubo diferencia significativa en el reemplazo electrolítico entre ambos grupos.

Conclusión: Se encontró una respuesta mayor con la bumetanida intermitente que con la bumetanida en perfusión continua. Este estudio apoya el ratio de dosis equivalente de 40:1

(furosemida:bumetanida) en pacientes con fallo cardiaco que reciben al menos 48 horas de bumetanida intravenosa intermitente. 
Palabras clave: Bumetanida; Furosemida; Fallo cardiaco; Resultado del Tratamiento; Equivalencia Terapéutica

\section{INTRODUCTION}

Intravenous (IV) loop diuretics serve an important role in the management of patients with volume overload in order to improve symptoms and optimize hemodynamic status. The role diuretics play is illustrated by their inclusion in guidelines for the management of acute and chronic heart failure, cirrhosis with ascites, renal insufficiency, and pulmonary hypertension. ${ }^{1-6}$ As the first of its class, furosemide has remained the loop diuretic of choice due to its efficacy and low cost. ${ }^{7,8}$ Additional loop diuretic agents include bumetanide and torsemide, which have been reported to have equipotent effects at IV doses of furosemide $40 \mathrm{mg}$ to bumetanide $1 \mathrm{mg}$ and torsemide $20 \mathrm{mg}$. $^{9-11}$

While diuresis is necessary in the management of a number of disease states, studies have repeatedly demonstrated the deleterious outcomes associated with these agents and a precise optimal dosing strategy has yet to be found., 6,12 The adverse effects of these agents are well documented and include volume depletion, ototoxicity, neurohormonal activation, and electrolyte abnormalities. High diuretic doses have also been associated with increased hospital length of stay and a dose-related increase in mortality in patients with heart failure. 9,10,12,14 The effects of overdiuresis may manifest as hypotension, decreased cardiac output, and decreased renal perfusion. Loop diuretic-induced decrease in renal blood flow is evident by an average increase in serum creatinine of $0.23 \mathrm{mg} / \mathrm{dL}$ and $0.14 \mathrm{mg} / \mathrm{dL}$ for intermittent and continuous infusion, respectively. ${ }^{9}$ Ototoxicity has been reported with all loop diuretics but may occur less often with bumetanide when compared to furosemide. ${ }^{10,14}$ Diuretic-induced electrolyte abnormalities predispose patients to fatal arrhythmias. Bumetanide, however, may have a less potent kaliuretic effect compared with furosemide. $^{10,15,16}$ The clinical significance of this difference is unclear, but theoretically could result in less arrhythmogenicity. Analysis of the Acute Decompensated Heart Failure National (ADHERE) Registry demonstrated an increased risk of intensive care unit length of stay greater than 3 days, total length of hospital stay greater than 4 days, and greater in-hospital mortality in patients who received higher doses of IV loop diuretics defined as furosemide-equivalent doses $\geq 160 \mathrm{mg}$ during the first 24 hours of hospital admission. ${ }^{17,18}$ Various studies have also demonstrated a positive correlation with chronic diuretic dose and mortality; however, among these studies inconsistency exists in the ratio used when converting doses from other loop diuretics to furosemide equivalent doses. ${ }^{13}$ How this may influence outcomes is unknown but is an important consideration, nonetheless.

Reported equipotent doses of furosemide and bumetanide range from $25: 1$ to $50: 1$ for oral dosing and $<30: 1$ and up to $50: 1$ for intravenous dosing in healthy patients or patients with a positive fluid balance due to disease states such as heart failure, cirrhosis with ascites, and chronic kidney disease. ${ }^{7,16,19}$ Small differences in the pharmacokinetic profiles of bumetanide and furosemide may influence the response to or toxicity of these agents. ${ }^{10,20}$ As loop diuretics, both are dependent on secretion via active transport into the renal tubules in order to reach their site of action at the sodium-potassium-chloride channels within the ascending loop of Henle. ${ }^{9}$ Compared with furosemide, bumetanide demonstrates greater and more consistent oral bioavailability, which is important in disease states such as heart failure, where oral absorption may be impaired. ${ }^{21-23}$ Both of these agents are highly protein bound and excreted renally, however bumetanide is thought to undergo non-renal elimination as well resulting in less accumulation in renal dysfunction when compared with furosemide. ${ }^{9,10,22,24}$ In patients with increased extracellular fluid and a greater volume of distribution, such as heart failure, chronic kidney disease, and cirrhosis with ascites, higher doses or shorter dosing intervals may be necessary in order to reach adequate drug concentration at the site of action. ${ }^{22}$ Higher doses compensate for a decrease in drug bioavailability and a higher volume of distribution, while shorter dosing intervals can be used to avoid the rebound sodium retention that occurs towards the end of the dosing interval in response to a decrease in intravascular volume. ${ }^{25}$ Despite these strategies and more aggressive dosing, a lower maximal diuretic effect is seen across edematous disease states. ${ }^{21}$

Given the dose-related adverse effects of these agents, thoughtful consideration must be taken when choosing a diuretic dose in order to achieve the maximum therapeutic benefit while minimizing adverse effects. Recently, due to a national shortage of IV furosemide, practitioners at the Medical University of South Carolina were forced to use IV bumetanide as the formulary loop diuretic for six months. With the increased utilization of IV bumetanide, we sought to retrospectively quantify the dose-response effect of continuous and intermittent dosing of IV bumetanide, compare the dose-response of IV bumetanide with IV furosemide in a subset of patients with HF, and to describe adverse effects seen with the use of bumetanide.

The primary objective of this study was to identify the dose-response effect of intermittent and continuous infusion bumetanide in all patients at our institution. We also sought to compare the potency of IV bumetanide to IV furosemide in a subset of patients with $\mathrm{HF}$, using data previously collected at our institution and described by Thomson and colleagues. ${ }^{26}$ The secondary objective of this study was to assess the safety profile of IV bumetanide with respect to electrolyte disturbances.

\section{METHODS}

\section{Study Design}

This was a retrospective, observational study that examined patients who received intravenous 
bumetanide for at least 48 hours from June 2010 through October 2010. At this time, the Medical University of South Carolina Medical Center implemented an automatic substitution for orders of IV furosemide to be converted to IV bumetanide at a ratio of $40: 1$. All patients in the hospital were eligible for this substitution. Patients were excluded from the study if they were less than 18 years old, received less than 48 hours of bumetanide, or did not have urine output recorded. This study was approved by the institution's investigational review board.

\section{Data Collection}

Data collection included patient demographic information, past medical history, admission diagnosis, length of hospital stay, and pertinent home and hospital medications. Data collected daily included total dose of bumetanide, intermittent (iIV) or continuous infusion (cIV) administration, total fluid intake and urine output (UOP), serum sodium, blood urea nitrogen, serum creatinine, albumin, and any doses of potassium or magnesium given for electrolyte replacement. Patient weight and B-type natriuretic peptide (BNP) were collected on admission and discharge when available.

The primary endpoint of this study was derived by calculating the average daily UOP per total daily dose of bumetanide received $(\mathrm{mL} / \mathrm{mg})$. This was done by using the sum of the total urine output during the study period for each patient and dividing by total drug received. Dividing this value $(\mathrm{mL} / \mathrm{mg})$ by the duration of therapy (days) for each patient gave the average daily UOP per $\mathrm{mg}$ of drug received for each patient. The mean (standard deviation; SD) of this number was reported as our primary outcome. In order to compare the potency of IV bumetanide to IV furosemide, a more homogenous patient population was chosen by selecting only those patients with systolic HF and comparing daily UOP per mg of drug administered to preexisting data describing this outcome with furosemide. ${ }^{26}$ The secondary objective of this study, an evaluation of safety, was measured by quantifying the average daily amount of electrolyte replacement administered while on therapy.

\section{Statistical Analysis}

Categorical data were reported as number of subjects (\%) while continuous variables, including the primary outcome and secondary safety objective comparing ilV bumetanide to cIV bumetanide, were reported as mean (SD). Data were analyzed for significant differences using the Mann-Whitney-U test. Potency ratios were calculated by dividing the primary outcome $(\mathrm{mL} / \mathrm{mg} /$ day) for bumetanide as described previously by the same measurement for furosemide. Sample size was based on number of patients available for analysis and feasibility of data analysis within a required time frame. A post hoc power analysis was done to confirm that sample sizes were adequate to reach a power of $80 \%$. Correlation analysis was performed using Spearman rank correlation with pairwise exclusion to identify independent variables associated with the primary outcome. A p-value of $<0.05$ was considered statistically significant. Data was analyzed using SPSS version 12.0 (SPSS, Chicago, Illinois, USA).

\section{RESULTS}

A total of 230 patients received intravenous bumetanide for at least 48 hours from June 1, 2010October 30, 2010. Of these, 109 patients were used in analysis of the primary outcome of bumetanide efficacy, after excluding patients who did not have urine output recorded or those who had doses held resulting in less than 48 hours of bumetanide therapy. Ninety-three patients $(85.3 \%)$ received intermittent dosing and 16 patients $(14.7 \%)$ received continuous infusion dosing. Of the 109 patients, 33 patients $(30.3 \%)$ had systolic HF and were used to compare the potency of bumetanide with furosemide (Figure 1).

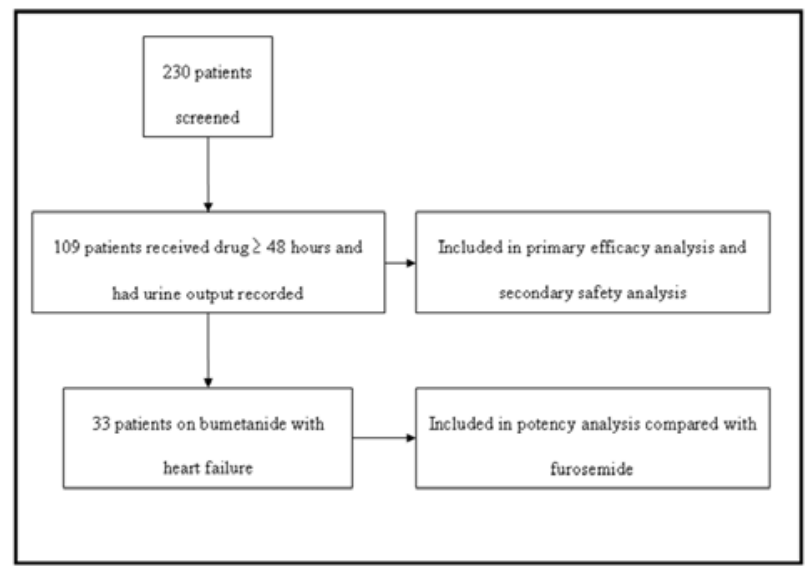

Figure 1. Flow chart showing patients included for analysis of outcomes

Baseline characteristics were similar between groups, as shown in Table 1 . Overall, $52.3 \%$ of patients were male and $54.1 \%$ Caucasian. All nonCaucasian patients were Black with the exception of one patient of Asian descent. The average age was $58.2(\mathrm{SD}=15.3)$ years. Nearly one-third $(33 \%)$ of the patients in the intermittent group versus $18.7 \%$ of the continuous group had a serum creatinine of 1.5 $\mathrm{mg} / \mathrm{dL}$ or greater at baseline. Serum sodium concentration was significantly higher in the ilV group at baseline. Medications taken prior to admission were available for $55 \%$ of patients and are shown in Table 2. Pertinent medications administered concomitantly with bumetanide are listed in Table 2, with beta-blockers, angiotensinconverting enzyme inhibitors or angiotensin receptor blockers, and dihydropyridine calcium channel blockers being the most frequently administered cardiac medications. Thirteen patients received concomitant thiazide diuretic with bumetanide, the majority of which $(62 \%)$ were in the cIV group. In order to determine if the use of thiazide diuretics impacted the results, the primary endpoint was also analyzed while excluding those patients that received a thiazide diuretic. This analysis required exclusion of $50 \%$ of patients in the cIV group and $5 \%$ of patients in the ilV group. Contrary to the overall primary endpoint, with exclusion of patients that received thiazide diuretics, 


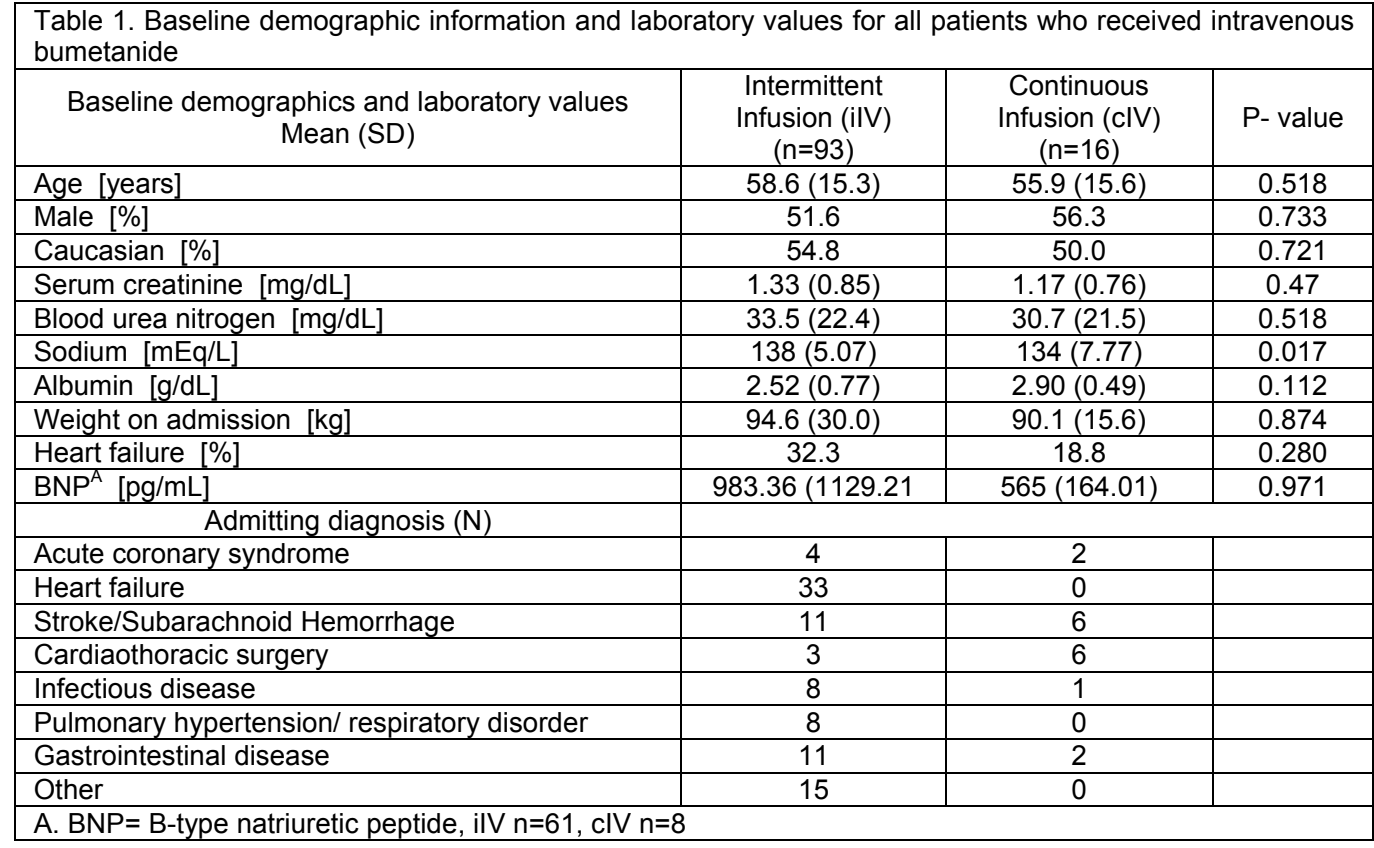

there was not a statistically significant difference between groups $(P=0.067)$. The average duration of therapy was five days for both the ilV and clV groups. Many of the baseline characteristics (age, race, serum creatinine) of patients in this study resemble those in the study by Thomson et al. However the populations differed in a major respect. The current study included patients with indications for diuresis beyond heart failure exacerbation.

As shown in Table 3, the mean daily dose of bumetanide and mean daily UOP were significantly higher in the clV group; however, the primary outcome (UOP/mg bumetanide) was significantly higher in the ilV group. Data were also analyzed using a weight-based primary outcome $(\mathrm{mL} / \mathrm{kg} / \mathrm{mg}$ bumetanide received); however, this did not influence the results. Patients with $\mathrm{HF}$, renal insufficiency (RI), both $\mathrm{HF}$ and $\mathrm{RI}(\mathrm{HF}+\mathrm{RI})$, or otherwise healthy patients were evenly distributed between the ilV and cIV groups. As shown in Figure 2 , the HF+RI group had the poorest response to bumetanide. Correlation analysis showed a statistically significant relationship between response to bumetanide $(\mathrm{mL} / \mathrm{mg})$ and average total daily dose $(P<0.001)$ and BNP $(P=0.017)$.

Based on previously published data, we were able to compare the dose-response effect of IV bumetanide to IV furosemide in patients with $\mathrm{HF} .^{26}$ Of the 33 patients with HF who received IV bumetanide, $30 \quad(90.9 \%)$ received intermittent dosing and $3(9.1 \%)$ received continuous infusion dosing. Contrary to the primary outcome in the total population, among patients with heart failure there was no difference in daily UOP per mg bumetanide received in the ilV and cIV groups at $897(S D=540)$ $\mathrm{mL} / \mathrm{mg}$ and $1074(\mathrm{SD}=721) \mathrm{mL} / \mathrm{mg}$, respectively. Table 4 shows the primary outcome result for the subgroup of patients with HF who received iIV or cIV bumetanide or furosemide. As published previously, intermittent furosemide dosing resulted in $22(\mathrm{SD}=13) \mathrm{mL} / \mathrm{mg}$ UOP $(\mathrm{n}=30)$ as compared with $38(\mathrm{SD}=31) \mathrm{mL} / \mathrm{mg}$ UOP $(\mathrm{n}=26)$ for continuous infusion furosemide. When comparing only the intermittent dosing strategies, there was a doseequivalence ratio of $41: 1$ between furosemide and bumetanide. In the entire subgroup of patients with $\mathrm{HF}$, the overall dose-equivalence ratio was $34: 1$.

\begin{tabular}{|l|c|c|}
\hline $\begin{array}{l}\text { Table 2. Patients' home medications taken prior to admission and those administered concomitantly with } \\
\text { intravenous bumetanide }\end{array}$ & $\begin{array}{c}\text { Hospital Medication } \\
(\mathrm{n}=109) \\
\mathrm{n}(\%)\end{array}$ \\
\hline Drug & $\begin{array}{c}\text { Home Medication } \\
(\mathrm{n}=60) \\
\mathrm{n}(\%)\end{array}$ & $13(12)$ \\
\hline Thiazide diuretic & $10(16.7)$ & $21(19.3)$ \\
\hline Potassium-sparing diuretic & $21(35.0)$ & $109(100)$ \\
\hline Loop diuretic & $37(61.7)$ & $13(12.0)$ \\
\hline Inotrope & $4(6.7)$ & $13(12.0)$ \\
\hline Vasopressor & $0(0)$ & $33(30.3)$ \\
\hline ACEi/ARB & $33(55.0)$ & $57(52.3)$ \\
\hline Beta-blocker & $32(53.3)$ & $11(10.1)$ \\
\hline Hydralazine & $4(6.7)$ & $8(7.3)$ \\
\hline Nitrate & $3(5.0)$ & $6(5.5)$ \\
\hline Nondihydropyridine CCB & $3(5.0)$ & $27(24.8)$ \\
\hline Dihydropyridine CCB & $12(20.0)$ & $8(0.9)$ \\
\hline Amiodarone & $1(1.7)$ & $8(7.3)$ \\
\hline Digoxin & $6(10.0)$ & \\
\hline ACEi= Angiotensin-converting enzyme inhibitor, ARB= Angiotensin receptor blocker, CCB= Calcium channel blocker \\
A. Inotrope: dobutamine or milrinone \\
B. Vasopressor: continuous infusion of epinephrine, norepinephrine, phenylephrine, dopamine, and/or vasopressin \\
\hline
\end{tabular}




\begin{tabular}{|l|c|c|c|}
\hline Table 3. Shown below is the primary outcome of urine output per mg of bumetanide per patient per day. \\
\hline & $\begin{array}{c}\text { Intermittent Infusion } \\
(\mathrm{n}=93)\end{array}$ & $\begin{array}{c}\text { Continuous Infusion } \\
(\mathrm{n}=16)\end{array}$ & P-value \\
\hline Mean (SD) total daily dose [mg] & $2.57(1.30)$ & $6.62(3.58)$ & $<0.001$ \\
\hline Mean (SD) daily urine output [mL] & $2575(1061)$ & $3990(1013)$ & $<0.001$ \\
\hline $\begin{array}{l}\text { Daily urine output per bumetanide dose } \\
\text { (SD) [mL/mg] }\end{array}$ & $1273(844)$ & $749(370)$ & 0.002 \\
\hline
\end{tabular}

Electrolyte disturbances with iIV and cIV bumetanide were measured as average potassium and magnesium electrolyte replacement per patient per day during the study period. There was no significant difference in mean electrolyte replacement between dosing strategies. The average potassium replacement was $23.3 \mathrm{mEq}$ per day versus $14.4 \mathrm{mEq}$ per day in the intermittent and continuous dosing groups respectively. The average magnesium replacement was 0.3 grams per day versus 0.2 grams per day in the intermittent and continuous dosing groups respectively Average daily potassium and magnesium replacement per patient per day $(n=109)$ were $22(S D=30) \mathrm{mEq}$ and $0.247(S D=0.557)$ grams, respectively.

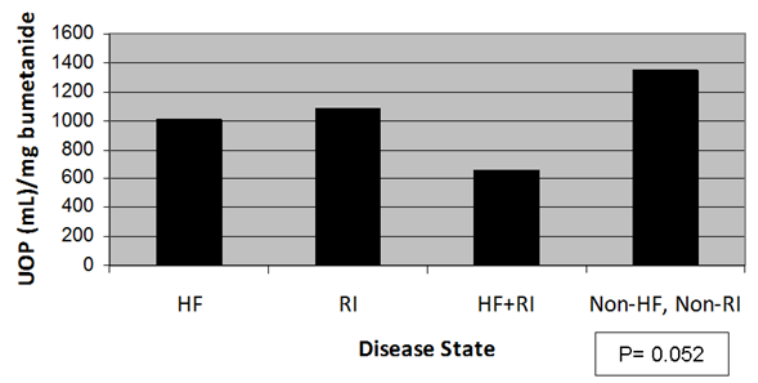

Figure 2. Bar graph showing the effect of bumetanide in patients with varying disease states

\section{DISCUSSION}

Our retrospective analysis was able to quantify the dose-response effect of IV bumetanide and found the intermittent dosing group to have a higher doseresponse effect. Variability in response was seen when comparing patients with $\mathrm{HF}$, RI, or otherwise healthy individuals, however significance was not able to be determined. As previously discussed, the low response seen in the HF+RI group may be due to various pharmacokinetic and pharmacodynamic changes in these patients making adequate diuresis more challenging. Lastly, these results uphold the 40:1 dose equivalence ratio for furosemide:bumetanide treated with intermittent dosing. The 40:1 ratio was diminished in those patients receiving continuous infusions.

In recent literature there have been many studies evaluating clinical outcomes that assume a diuretic equivalence ratio other than the well-accepted 40:1 ratio. For example, Eshagian and colleagues evaluated independent predictors of mortality in patients with advanced heart failure. ${ }^{12}$ Chronic diuretic dose, reported as furosemide equivalents, proved to be an independent predictor of mortality. In this study oral furosemide $80 \mathrm{mg}$ was considered equal to bumetanide $3 \mathrm{mg}$. Assuming an approximate bioavailability of $50 \%$ for oral furosemide, this ratio may have underestimated the average daily dose of patients on chronic bumetanide therapy. More recently, the authors of the Diuretic Optimization Strategies Evaluation (DOSE) trial evaluated four different dosing strategies for patients hospitalized with acute decompensate heart failure. ${ }^{13}$ Patients were converted from their home loop diuretic to what was considered an equivalent IV dose, using a dose conversion of oral furosemide $40 \mathrm{mg}$ to oral torsemide $20 \mathrm{mg}$ and oral bumetanide $1 \mathrm{mg}$. If the oral bioavailability of furosemide was taken into consideration and assumed to be $50 \%$, then a ratio of 80:20:1 for oral furosemide:torsemide:bumetanide would have been closer to the accepted IV ratio of $40: 1 .^{11,22}$ The ratio used in the DOSE trial may have resulted in lower doses of IV furosemide for patients admitted when doses were calculated based on their home dose of torsemide or bumetanide. This hypothesis is limited due to the highly variable oral bioavailability of furosemide.

There are a number of limitations to our study. As a retrospective study it was not possible to control for baseline characteristics, acuity of illness and concomitant medications administered. Twelve percent of patients receiving IV bumetanide also received a thiazide diuretic during the study period; the results of the subgroup analysis excluding those patients that received a thiazide diuretic must be interpreted with caution due to the number of patients that had to be excluded from the cIV group $(50 \%)$. Little can be concluded from this subgroup analysis except that those patients receiving a thiazide diuretic were poor responders to any form of diuretic therapy. Additionally, because randomization was not possible, we do not know how many patients in the clV group may have previously failed intermittent dosing. If more patients in the cIV group failed intermittent therapy, it may offer a reason for the cIV group having a poorer response than the ilV group, as seen in this study. One would expect to see equal or improved efficacy in the continuous infusion bumetanide group when compared to intermittent dosing because of the

Table 4. Comparison of potency between bumetanide and furosemide in patients with heart failure, analyzed as intermittent dosing or continuous dosing and total population.

\begin{tabular}{|l|c|c|c|}
\hline & $\begin{array}{c}\text { Intermittent } \\
\text { IV infusion (ilV) }\end{array}$ & $\begin{array}{c}\text { Continuous IV } \\
\text { infusion (cIV) }\end{array}$ & $\begin{array}{c}\text { All patients } \\
\text { with heart } \\
\text { failure }\end{array}$ \\
\hline Bumetanide UOP per mg drug [mL/mg] mean (SD) & $897(540)$ & $1074(721)$ & $1010(579)$ \\
\hline Furosemide UOP per mg drug [mL/mg] mean (SD) & $22(13)$ & $38(31)$ & $30(24)$ \\
\hline Furosemide:Bumetanide equivalence ratio & $41: 1$ & $27: 1$ & $34: 1$ \\
\hline UOP: urine output; ilV bumetanide $\mathrm{n}=30, \mathrm{cIV}$ bumetanide $\mathrm{n}=3$, ilV furosemide $\mathrm{n}=30$, clV furosemide $\mathrm{n}=26$ \\
\hline
\end{tabular}


higher doses used and the avoidance of potential rebound sodium reabsorption between intermittent doses. $^{22}$ The lower UOP per mg drug received in the cIV bumetanide group could not be explained by a higher percentage of patients with HF or RI, who may have required higher doses to achieve similar UOP. Further, because the baseline serum sodium was lower in the clV group, it may be hypothesized that this group had a more severe degree of volume overload, necessitating, but not manifesting in a greater need for diuresis. Therefore, we can only hypothesize this difference to be due to the small number of patients in the clV bumetanide group and/or a higher percentage of diuretic resistant patients as discussed above. We had to assume that urine output was accurately recorded in the patient's medical record. Further, we used electrolyte replacement as a surrogate marker to measure the potential for adverse effects such as arrhythmias. Because of the retrospective nature of the study we were not able to appropriately assess other potential adverse reactions of loop diuretics including increases serum creatinine, hyponatremia, hypotension, ototoxicity, and myalgias. Another limitation of this study was the exclusion of $53 \%$ of the originally identified patient population. The reason for this was multifactorial including both limitations in retrospective data collection and the technology used to identify potential patients. Retrospective data collection did not allow for regulation of urine output monitoring and poor records led to the exclusion of many patients. These patients may not have had UOP quantified for multiple reasons including absence of a specific physician order, location outside of an intensive care unit, or not having a foley catheter in place resulting in UOP recorded only as an "occurrence." The electronic pharmacy computer system used to generate a list of patients on bumetanide therapy for at least 48 hours did so based on number of doses dispensed. Because of medication barcode administration we were able to determine the actual number of doses administered, which at times was less than the number of doses dispensed and, thus resulted in less than 48 hours of therapy. The limitations of this study are reflected in the wide variability of our results, represented by large standard deviations. It also must be considered that these data may not be applicable to patients receiving less than 48 hours of therapy.

Clear limitations also apply when comparing new data to the previously collected data by Thomson and colleagues. ${ }^{26}$ The prospective multicenter study of Thomson et. al. may have allowed for better control of baseline characteristics and recording of data. The different study designs and time frames used in each study limit the ability to accurately compare and scientifically analyze the potency of bumetanide and furosemide.

\section{CONCLUSIONS}

With our retrospective data we have quantified the dose-response effect of IV bumetanide and compared the potency with IV furosemide in patients with heart failure. While our study supports the 40:1 equipotent dosing for intermittent intravenous furosemide:bumetanide, further prospective data are needed in order to establish the true dose-response effect of continuous infusion bumetanide dosing. We should consider this ratio when interpreting literature that may have used alternative ratios in data analysis. We propose that clinicians should continue to utilize the intravenous dose equivalence ratio of 40:1 when transitioning patients between intravenous furosemide and bumetanide. Future studies may be beneficial to evaluate the efficacy of bumetanide in furosemideresistant patients and determine appropriate dosing strategies in edematous patients.

\section{ACKNOWLEDGEMENTS}

The author would like to recognize the contribution of Mary Bradbury, PharmD to this project.

\section{CONFLICT OF INTEREST}

The author has no conflicts of interest to disclose.

This project was not funded.

\section{References}

1. Ginés P, Cárdenas A, Arroyo V, Rodés J. Management of cirrhosis and ascites. New Engl J Med. 2004;350(16):164654. doi: 10.1056/NEJMra035021

2. Runyon BA. Management of adult patients with ascites due to cirrhosis: an update. American Association for the Study of Liver Disease Practice Guidelines. Hepatology. 2009;49(6):2087-107. doi: 10.1002/hep.22853

3. Kidney Disease Outcomes Quality Initiative (K/DOQI). Clinical Practice Guidelines on Hypertension and Antihypertensive Agents in Chronic Kidney Disease. Am J Kidney Dis. 2004;43(5 Suppl 1):S1-290.

4. McLaughlin VV, Archer SL, Badesch DB, Barst RJ, Farber HW, Lindner JR, Mathier MA, McGoon MD, Park MH, Rosenson RS, Rubin LJ, Tapson VF, Varga J.. ACCF/AHA 2009 expert consensus document on pulmonary hypertension: a report of the American College of Cardiology Foundation Task Force on Expert Consensus Documents and the American Heart Association developed in collaboration with the American College of Chest Physicians; American Thoracic Society, Inc.; and the Pulmonary Hypertension Association. J Am Coll Cardiol. 2009;53(17):1573619. doi: 10.1016/j.jacc.2009.01.004.

5. Puschett JB. Pharmacological classification and renal actions of diuretics. Cardiology. 1994;84(Suppl 2):4-13.

6. Jessup M, Abraham WT, Casey DE, Feldman AM, Francis GS, Ganiats TG, Konstam MA, Mancini DM, Rahko PS, Silver MA, Stevenson LW, Yancy CW. 2009 Focused update: ACCF/AHA guidelines for the diagnosis and management of heart failure in adults: a report of the American College of Cardiology Foundation/American Heart Association Task Force on Practice Guidelines: Developed in Collaboration with the International Society for Heart and Lung Transplantation. J Am Coll Cardiol 2009;53(15):1343-1382. doi:10.1016/j.jacc.2008.11.009 
7. Konecke LL. Clinical trial of bumetanide versus furosemide in patients with congestive heart failure. $\mathrm{J}$ Clin Pharmacol. 1981;21(11-12 Pt 2):688-90.

8. Dixon DW, Barwolf-Gohlke C, Gunnar RM. Comparative efficacy and safety of bumetanide and furosemide in long-term treatment of edema due to congestive heart failure. J Clin Pharmacol. 1981;21(11-12 Pt 2):680-7.

9. Cleland JGF, Coletta A, Witte K. Practical applications of intravenous diuretic therapy in decompensated heart failure. Am J Med. 2006;119(12 Suppl 1):S26-36.

10. Ward A, Heel RC. Bumetanide: A review of its pharmacodynamic properties and therapeutic use. Drugs. 1984;28(5):426-64.

11. Product information. Bumex (Bumetanide). Bedford, OH: Bedford Laboratories; February 2010.

12. Eshaghian S, Horwich TB, Fonarow GC. Relation of loop diuretic dose to mortality in advanced heart failure. Am $\mathrm{J}$ Cardiol. 2006;97(12):1759-64.

13. Felker GM, Lee KL, Bull DA, Redfield MM, Stevenson LW, Goldsmith SR, LeWinter MM, Deswai A, Rouleau JL, Ofili EO, Anstrom KJ, Hernandez AF, McNulty SE, Velaquez EJ, Kfoury AG, Chen HH, Givertz MM, Semigran MJ, Bart BA, Mascette AM, Braunwald E, O'Connor CM for the NHLBI Heart Failure Clinical Research Network. Diuretic strategies in patients with acute decompensated heart failure. N Engl J Med. 2011;364(9):797-805. doi: 10.1056/NEJMoa1005419.

14. Whelton A. Long-term bumetanide treatment of renal edema. Comparison with furosemide. J Clin Pharmacol. 1981;21(11-12 Pt 2):591-8.

15. Hutcheon DE, Vincent ME, Sandhu RS. Renal electrolyte excretion pattern in response to bumetanide in healthy volunteers. J Clin Pharmacol. 1981;21(11-12 Pt 2):604-9.

16. Brater DC, Fox WR, Chennavasin P. Electrolyte excretion patterns. Intravenous and oral doses of bumetanide compared to furosemide. J Clin Pharmacol. 1981;21(11-12 Pt 2):599-603.

17. Peacock WF, Costanzo MR, De Marco T, Lopatin M, Wynne J, Mills RM, Emerman CL for the ADHERE Scientific Advisory Committee and Investigators. Impact of intravenous loop diuretics on outcomes of patients hospitalized with acute decompensated heart failure: Insights from the ADHERE registry. Cardiology. 2009;113(1):12-9. doi: $10.1159 / 000164149$.

18. Fonarow GC, Peacock WF, Horwich TB, et al.: ADHERE Scientific Advisory Committee and Investigators. Usefulness of B-type natriuretic peptide and cardiac troponin levels to predict in-hospital mortality from ADHERE. Am J Cardiol. 2008;101(2):231-7. doi: 10.1016/j.amjcard.2007.07.066.

19. Berg KJ, Tromsdal A, Wideroe TE. Diuretic action of bumetanide in advanced chronic renal insufficiency. Eur $\mathrm{J}$ Clin Pharmacol. 1976;9(4):265-75.

20. Voelker JR, Cartwright-Brown D, Anderson S, Leinfelder J, Sica DA, Kokko JP Brater DC. Comparison of loop diuretics in patients with chronic renal insufficiency. Kidney Int. 1987;32(4):572-8. doi: 10.1038/ki.1987.246

21. Brater DC, Day B, Burdette A, Anderson S. Bumetanide and furosemide in heart failure. Kidney Int. 1984;26(2):183-9.

22. Brater DC. Diuretic therapy. N Engl J Med. 1998;339(6):387-95.

23. McCrindle JL, Li Kam Wa TC, Barron W, Prescott LF. Effect of food on the absorption of furosemide and bumetanide in man. Br J Clin Pharmacol. 1996;42(6):743-6.

24. Marcantonio LA, Auld WH, Murdoch WR, Purohit R, Skellern GG, Howes CA. The pharmacokinetics and pharmacodynamics of the diuretic bumetanide in hepatic and renal disease. Br J Clin Pharmacol. 1983;15(2):245-52.

25. Almeshari K, Ahlstrom NG, Caparo FE, Wilcox CS. A volume-independent component to postdiuretic sodium retention in humans. J Am Soc Nephrol. 1993;3(12):1878-83.

26. Thomson MR, Nappi JM, Dunn SP, Hollis IB, Rodgers JE, Van Bakel AB. Continuous versus intermittent infusion of furosemide in acute decompensated heart failure. J Card Fail. 2010;16(3):188-93. doi: 10.1016/j.cardfail.2009.11.005 